\title{
Strategies for the application of a conjugate gradient FWI algorithm of shallow environments.
}

\author{
Allan Segovia Spadini, (IAG/USP), Liliana Alcazar Diogo (IAG/USP), Evert Slob (TUDelft), Renato Luiz Prado (IAG/USP) \\ Copyright 2016, SBGf - Sociedade Brasileira de Geofisica
}

Este texto foi preparado para a apresentação no VII Simpósio Brasileiro de Geofísica, Ouro Preto, 25 a 27 de outubro de 2016. Seu conteúdo foi revisado pelo Comitê Técnico do VII SimBGf, mas não necessariamente representa a opinião da SBGf ou de seus associados. É proibida a reprodução total ou parcial deste material para propósitos comerciais sem prévia autorização da SBGf

\begin{abstract}
In this work we evaluate different strategies for the model update inside a FWI algorithm. It is know that the S wave velocity parameter is the one with greater sensitivity in a data covered by surface waves. The studied strategies, however, attempt to recover the $P$ wave velocity and the density models in different ways. We compared the pure optimization through a conjugate gradient algorithm with the direct calculation assuming a constant Poisson ratio and by Gardner equation. The results show good performance of the both methodologies in simple 1D models. More research is necessary in more complex situations.
\end{abstract}

\section{Introduction}

In a shallow situation where most of the data is covered by surface waves the $S$ wave velocity (Vs) is the parameter with greater influence in the Full Waveform Inversion (FWI) of seismic data. However we may which to obtain the $\mathrm{P}$ wave velocity $(\mathrm{Vp})$ and the density $(\rho)$ and also a good knowledge of the such models can provide a better response in the inversion of $\mathrm{Vs}$.

Recently the application subject of seismic FWI to shallow $(0-100 \mathrm{~m})$ situations has been studied by different authors. In Romdhane et al. (2011) a 2D elastic frequency domain algorithm was applied to a synthetic situation with complex topography. In the papers of Tran \& Hiltunen (2012a) and Tran \& Hiltunen (2012b) global search algorithms, were applied in search of more restricted models in a shallow subsurface situation. Tran \& McVay (2012) applied the FWI to invert the $S$ wave velocities with a Gauss-Newton 2D FWI algorithm in time domain. Other important papers are from Tran et al. (2013), Bretaudeau et al. (2013), Groos et al. (2014) and Amrouche \& Yamanaka (2015). Most of these applications seek for a $S$ wave velocity model in a very shallow subsurface working with a restricted frequency and offset range where most of the information of the seismograms concerns Rayleigh waves.

In the work of Groos (2013) a broad study of this subject was performed using a conjugate gradient FWI code. The application of this type of algorithm can fail in the determination of all three parameters together $(\mathrm{Vp}, \mathrm{Vs}$ and $\rho$ ) and a good knowledge of $\mathrm{Vp}$ and $\rho$ parameters is necessary when the Vs model is inverted. This type of problem is common also when Ocean-bottom cables
(OBC) data is used in inversion and was studied by Raknes \& Arntsen (2014). They evaluate the usage of different strategies such as the update of the models by relations such Vp/Vs ratio and Gardner's relation.

In here we evaluate the above mentioned strategies in a shallow subsurface situation where most of the data is covered by surface waves.

\section{Methodology}

For the application of the conjugate gradient algorithm we use the DENISE package developed by Köhn (2011). The code uses finite difference anelastic modeling as the forward solver.

The conjugate gradient method pursues the decent direction of the conjugate $\Delta c_{k}$ instead of $\Delta m_{k}$ which makes its convergence faster than simple steepest decent algorithms. This can be written as

$$
\Delta c_{k}=\Delta m_{k}+\beta_{k} \Delta c_{k-1}
$$

The first iteration of the algorithm uses the steepest decent direction:

$$
m_{1}=m_{0}+\alpha \Delta m_{0}
$$

The following iterations are calculated by (1). The weight factor $\beta$ can be calculated in different ways. One example is the Fletcher-Reeves form:

$$
\beta_{n}=\frac{\Delta m_{k}^{T} \Delta m_{k}}{\Delta m_{k-1}^{T} \Delta m_{k-1}}
$$

The original version of the DENISE code can be used to seek the three parameters $V p, V s$, and density at the same time or one or two parameters assuming that the others are known. The problem is solved in time domain and the code offers the possibility of frequency filtering through iterations.

A way to avoid the calculation of the $P$ wave velocity is to use a relation between $P$ and $S$ wave velocities and use the conjugate gradient just for the $S$ wave velocity. Such type of relation can be the $\mathrm{Vp} / \mathrm{Vs}$ ratio or the Poisson's ratio which can be written as

$$
v=\frac{1\left(V_{P} / V_{S}\right)^{2}-2}{2\left(V_{P} / V_{S}\right)^{2}-1}
$$

According to Karray \& Lefebvre (2008) Poisson's ratio has a relation with the dispersion curve of surface waves. And assuming that the Poisson's ratio is constant through the model this parameter can be estimated prior to the 
conjugate gradient algorithm. The estimate can be performed using a simple inversion procedure or through a library of dispersion curves comparison as in Socco \& Comina (2015).

To update the density model the Gardner (GARDNER; GARDNER; GREGORY, 1974) equation can be used:

$$
\rho=\alpha V_{P}^{\beta}
$$

where the parameters $\alpha$ e $\beta$ need to be determined based on a previous knowledge of the studied region. We performed modifications in the DENISE code to make the tests of such relations possible.

\section{Synthetic results}

In the synthetic tests we created a simple 2D model where a constant Possion ratio is observed in the entire model. The density can also be estimated using the same constant Gardner relation in the entire model. The value used for Poisson ratio was 0.3 and for the Gardner relation we use an $\alpha$ value of 194.0 and a $\beta$ value of 0.3 . The models used in as the observed model and the initial model are showed in Figures 1 and 2 respectively. The initial model is a smoothed version of the observed. For brevity only the Vs models are showed.

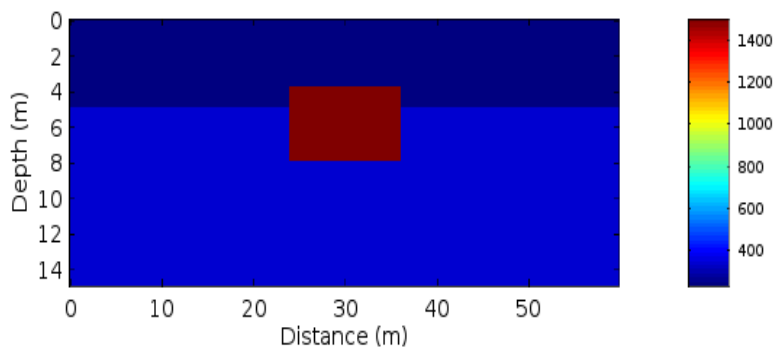

Figure 1: $S$ wave velocity model used as the observed model in the synthetic tests.

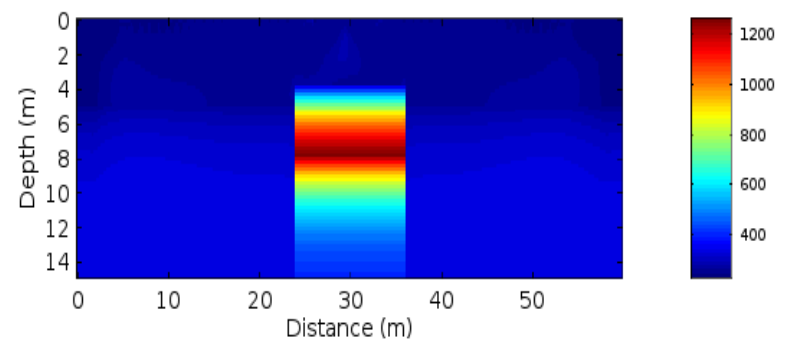

Figure 2: $S$ wave velocity model used as the initial model in the synthetic tests.

We use three different shots at positions 5, 29.5 and 54 meters. The receivers were 48 ranging from the distance position 6 to 53 meters. We assume constant attenuation and $Q p=Q$ s values of 20 . These values were assumed to be known. During the inversion we use frequency filtering beginning at $10 \mathrm{~Hz}$ and finishing at $70 \mathrm{~Hz}$. The filtering frequency changes if the relative misfit change between two iterations is smaller than 0.01 . We use an L2 norm to measure the objective function.

In the first test we estimate only the $V s$ with the unknown models $\mathrm{Vp}$ and $\rho$ given by the initial models (Figure 3 ). The second test uses the conjugate gradient to estimate $\mathrm{Vs}$ and $\mathrm{Vp}$ models with an unknown $\rho$ model (Figure 4) and in the third test all three models are estimated using the conjugate gradient algorithm (Figure 5). The fourth test estimates the Vs model using the conjugate gradient and the $\mathrm{Vp}$ model is estimated using the Poisson ratio (Figure 6). Finally the last test estimates the $S$ wave velocity using the conjugate gradient, the $\mathrm{Vp}$ model with the Poisson ratio and the density model using the Gardner relation (Figure 7). In the last two tests the correct values of Poisson ratio and Gardner relation were used.

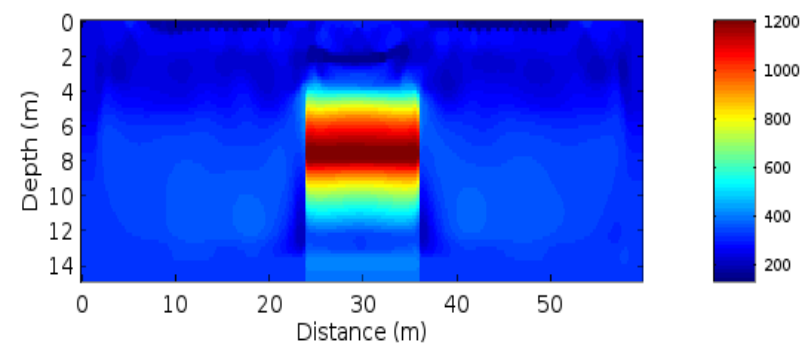

Figure 3: $S$ wave velocity model obtained in the first test.
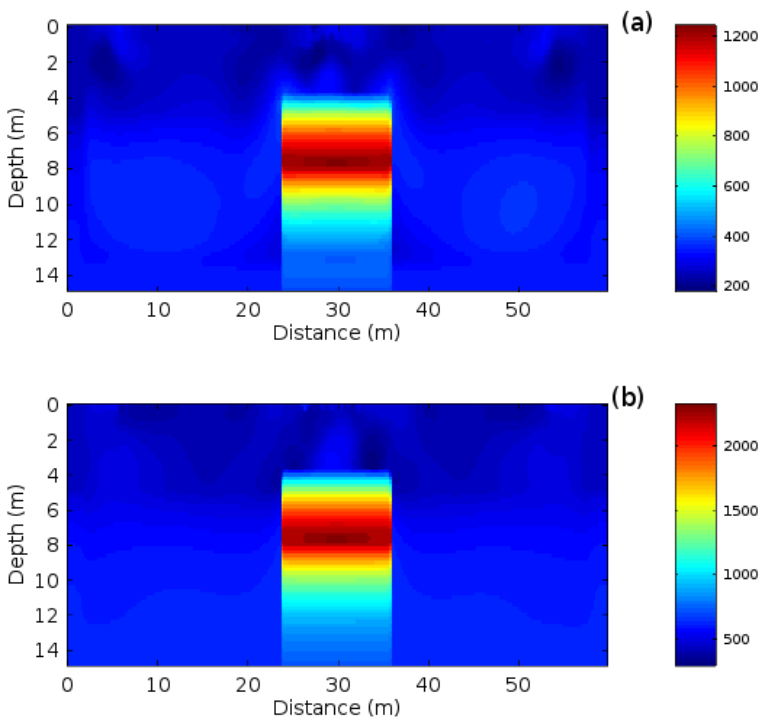

Figure 4: (a) $S$ wave velocity model; (b) $P$ wave velocity model; obtained in the second test.

The results generated in these first tests are important to analyze the behavior of the 2D solution. In the tests 2 and 3 the $\mathrm{Vp}, \mathrm{Vs}$ and $\rho$ models may show small differences since each one is calculated by the conjugate gradient method. In the tests 4 and 5 only the Vs models are show 
since the $\mathrm{Vp}$ and density models are calculated based in the Vs models and the 2D image will have the same form with different values. To better observe the precision of the results we took a vector at the distance position of 30 meters from each obtained model. These results are expressed in Figure 8.
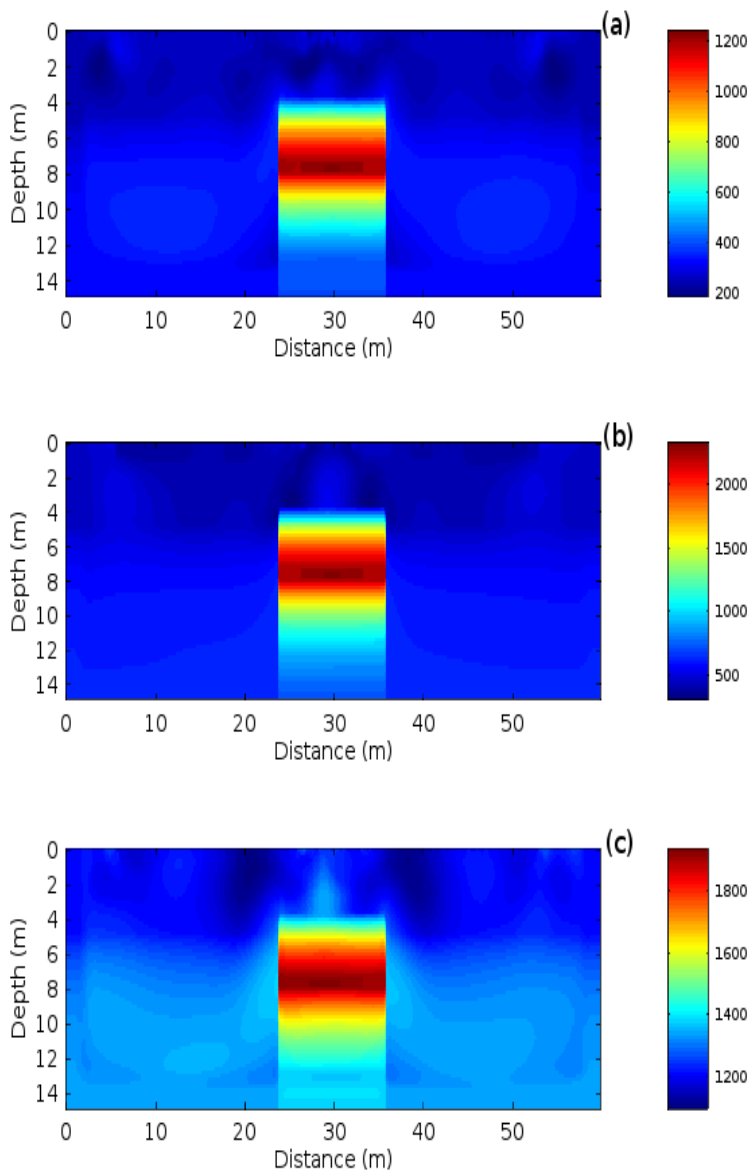

Figure 5: (a) $S$ wave velocity model; (b) $P$ wave velocity model; (c) Density model; obtained in the third test.

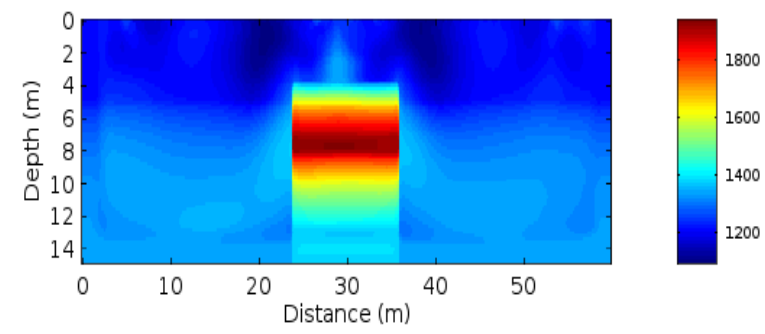

Figure 6: S wave velocity model obtained in the fourth test.

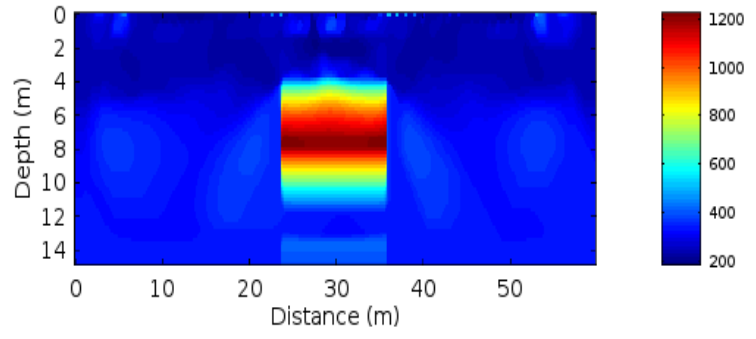

Figure 7: $S$ wave velocity model obtained in fifth test.
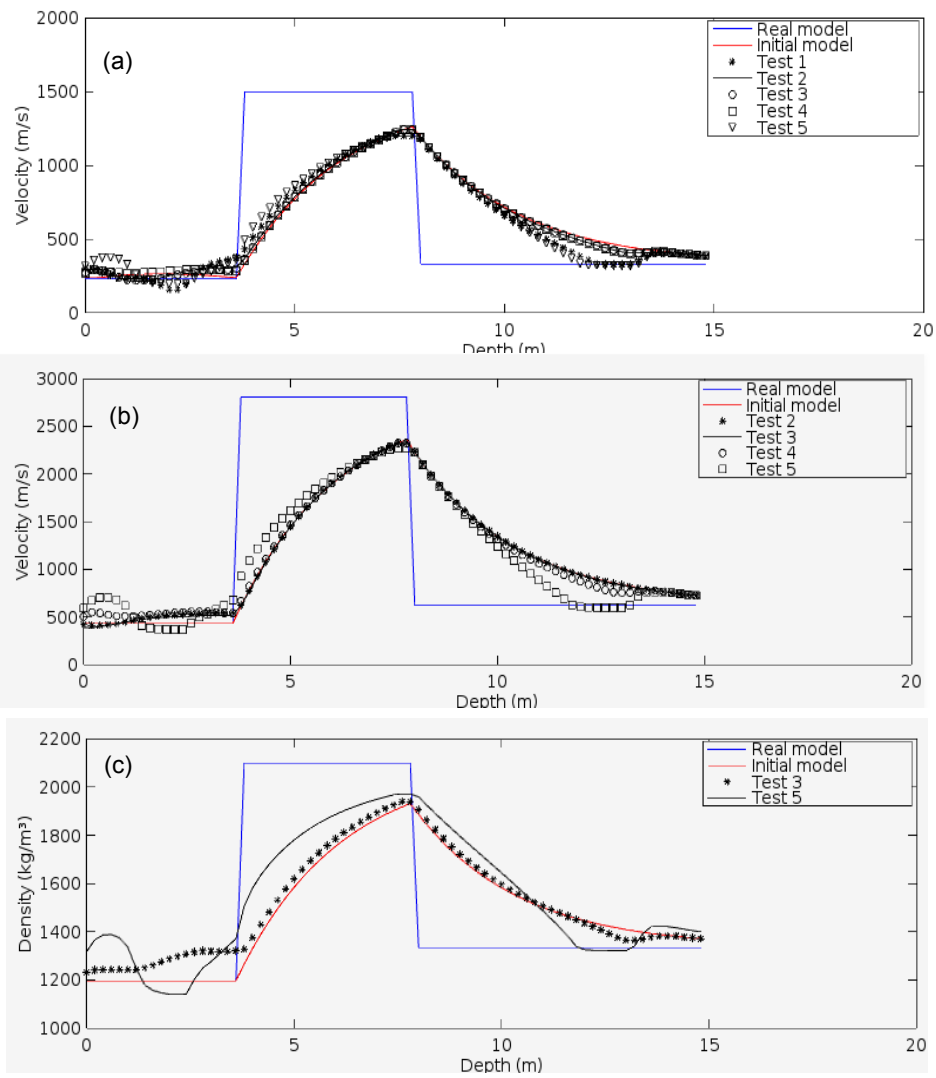

Figure 8: Vertical profiles extracted from figures 1 to 7 at the distance position of 30 meters. (a) Vs results; (b) Vp results; (c) $\rho$ results.

The profiles presented in Figure 8 show that the inversion almost doesn't move toward the solution. The profiles that show bigger curve modification are the ones related to the inversion that uses the conjugate gradient together with the Poisson ratio and Gardner relation. This methodology was then studied in more detail in comparison with the conjugate gradient estimate of all parameters.

In the following tests the same model from Figure 1 without the rectangle object at the center was used as the model that generates the observed data. This model was also used to create the initial models by adding perturbations to the model values. The results expressed in the Figure 9 had a $5 \%$ of perturbation added in the original models values and in Figure 10 a $10 \%$ perturbation is added. 
These results show that both methodologies work in more simple models with good initial guesses.
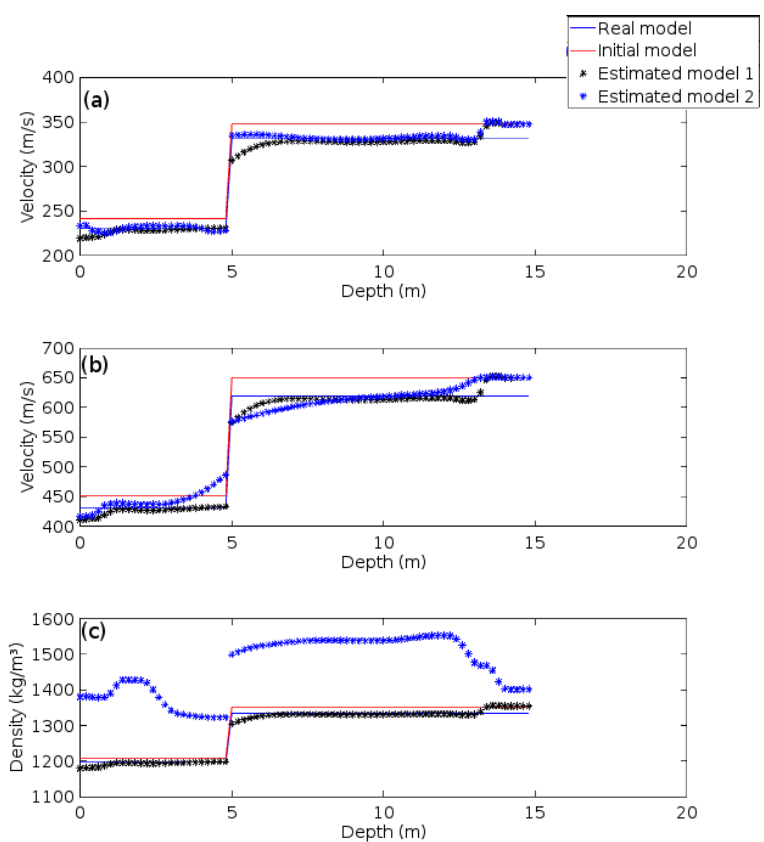

Figure 9: Results for inversion with an initial guess with $5 \%$ of perturbation in comparison with the real model. (a) Vs models; (b) Vp models; (c) Rho models. The estimated model 1 is the conjugate gradient with Poisson's ratio and Gardner equation. Estimated model 2 is the pure conjugate gradient optimization.
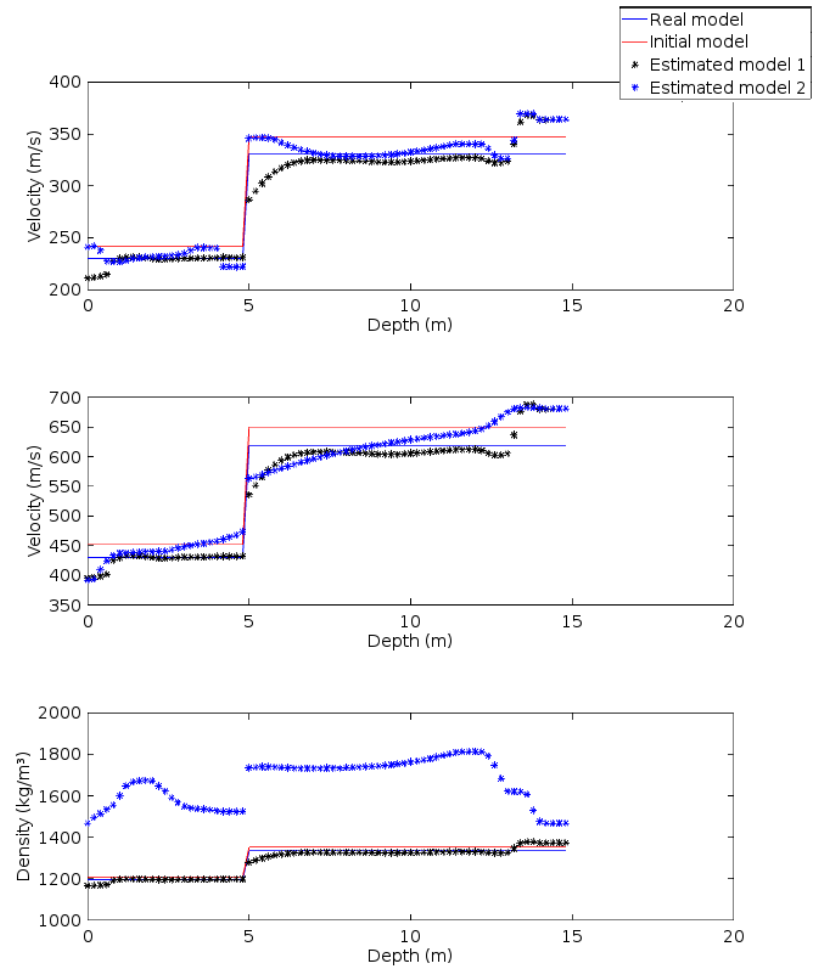

Figure 10: Results for inversion with an initial guess with $10 \%$ of perturbation in comparison with the real model. (a) Vs models; (b) Vp models; (c) Rho models. . The estimated model 1 is the conjugate gradient with Poisson's ratio and Gardner equation. Estimated model 2 is the pure conjugate gradient optimization.

\section{Comments e Conclusion}

The results in the 2D models obtained in tests 1 to 5 show that more studies are necessary regarding what type of initial model is more adequate to a more complex example. Is also necessary to verify if there are improvements that can be made the methodologies analyzed so then can handle this problem with the type of initial guess that was used. The estimates almost don't deviate from the initial guess, probably because the initial guess is too far in this case. The images from Figures 3 to 7 show small anomalies related with the shot positions which is a problem that must be addressed.

In the final results (Figures 9 and 10) the methodology that use the conjugate gradient for the estimation of all parameters and the methodology that use the Poisson ratio and Gardner equation show similar answers. In Figure 10 the result for the pure conjugate gradient optimization seems to deviate more from the desired result. The parameter that shows a greater difference between estimates is the density. This parameter is known for its low sensitivity in this type of problem. Thus, this shows one advantage of the application of the conjugate gradient together with Poisson's ratio and Gardner equations.

The differences in application of these methods must consider then the final desired result. Situations where the ratios of parameters have great variations, for example, may favor an application of the pure conjugate gradient estimation. In contrast when the parameter ratios are known or can be estimated the application that uses equations may help in the stabilization of the problem and to obtain an improved result for density measures.

\section{Acknowledgments}

Spadini agrece ao CNPq (Processo no. 406653/2013-5) pela bolsa de auxlio financeiro.

\section{Referências}

AMROUCHE, M.; YAMANAKA, H. Two-dimensional shallow soil profiling using time-domain waveform inversion. GEOPHYSICS, v. 80, n. 1, p. EN27-EN41, jan 2015. ISSN 0016-8033. Disponível em: <http://library.seg.org/doi/abs/10.1190/geo2014-0027.1>.

Bretaudeau, F., Brossier, R., Leparoux, B., Operto, S., Abraham, O. \& Virieux, J., 2013. 2D elastic full waveform imaging of the near surface: application to a physical scale model, Near Surf. Geophys., 11, 307-316.

GARDNER, G. H. F.; GARDNER, L. W.; GREGORY, A. R. FORMATION VELOCITY AND DENSITY-THE DIAGNOSTIC BASICS FOR STRATIGRAPHIC TRAPS.

GEOPHYSICS, v. 39 , n. 6 , p. $770-780$, dec 1974. ISSN 0016-8033. Disponível em: <http://library.seg.org/doi/abs/10.1190/1.1440465>.

GROOS, L. et al. The role of attenuation in 2D fullwaveform inversion of shallow-seismic body and Rayleigh waves. GEOPHYSICS, v. 79, n. 6, p. R247-R261, nov 
Allan Spadini, Liliana Diogo, Evert Slob, Renato Prado

2014. ISSN 0016-8033. Disponível em:

<http://library.seg.org/doi/abs/10.1190/geo2013-0462.1>.

KARRAY, M.; LEFEBVRE, G. Significance and evaluation of Poisson's ratio in Rayleigh wave testing. Canadian Geotechnical Journal, v. 45, n. 5, p. 624-635, may 2008. ISSN 0008-3674. Disponível em: $<$ http://dx.doi.org/10.1139/T08-

016http://www.nrcresearchpress.com/doi/abs/10.1139/T0 8-016>.

KÖHN, D. Time Domain 2D Elastic Full Waveform Tomography. 191 p. Tese (Doutorado) - ChristianAlbrechts-Universität zu Kiel, 2011

ROMDHANE, A. et al. Shallow-structure characterization by 2D elastic full-waveform inversion. Geophysics, v. 76, n. 3, p. R81-R93, 2011.

TRAN, K. T.; HILTUNEN, D. R. One-Dimensional Inversion of Full Waveforms using a Genetic Algorithm. Journal of Environmental \& Engineering Geophysics, v. 17, p. 197-213, 2012.

TRAN, K. T.; HILTUNEN, D. R. Two-Dimensional Inversion of Full Waveforms Using Simulated Annealing. Journal of Geotechnical and Geoenvironmental Engineering, v. 138, n. 9, p. 1075-1090, sep 2012. ISSN 1090-0241. Disponível em: $<$ http://ascelibrary.org/doi/abs/10.1061/\{\\%\}28ASCE\{ \%\}29GT.1943-5606>.

TRAN, K. T.; MCVAY, M. Site characterization using Gauss-Newton inversion of 2-D full seismic waveform in the time domain. Soil Dynamics and Earthquake Engineering, Elsevier, v. 43, p. 16-24, dec 2012. ISSN 02677261.Disponível em: <http://linkinghub.elsevier.com/retrieve/pii/S02677261120 01613>.

TRAN, K. T. et al. Sinkhole detection using 2D full seismic waveform tomography. v. 78, n. 5, p. 175-183, 2013. ISSN 00168033. 